Article

\title{
Local Level Stormwater Harvesting and Reuse: A Practical Solution to the Water Security Challenges Faced by Urban Trees
}

\section{Peter W. B. Nichols ${ }^{\dagger, *}$ and Terry Lucke ${ }^{\dagger}$}

Stormwater Research Group, University of the Sunshine Coast, 90 Sippy Downs Drive, Sippy Downs, Maroochydore, Queensland 4550, Australia; E-Mail: tlucke@usc.edu.au

$\dagger$ These authors contributed equally to this work.

* Author to whom correspondence should be addressed; E-Mail: pnichols@usc.edu.au; Tel.: +61-7-5456-5787; Fax: +61-7-5430-2881.

Academic Editor: Vincenzo Torretta

Received: 4 May 2015 / Accepted: 30 June 2015 / Published: 2 July 2015

\begin{abstract}
Water Sensitive Urban Design (WSUD) treatment devices are often used to restore natural drainage properties in developed catchments. WSUD can make positive contributions to the restoration of natural ecosystem processes, by supporting trees and habitats in urban areas without taking up limited urban space. This paper reports on the development and testing of a new WSUD device, the Wicking Tank. It is designed to supply sufficient volumes of water to urban trees through periods of drought via synthetic wicks from an underground storage tank to support adequate tree health. Relying on gravity fed stormwater, and the natural capillarity, adhesion, and cohesion properties of water and the process of hydraulic redistribution, water is transferred from the tank and into the rhizosphere of the tree. Water demand is controlled passively by the water potential differential across the root zone. Proof of concept testing of the Wicking Tank has shown the device to successfully draw water into soil to support the ongoing survival of a potted plant for over 20 weeks. Substantial differences are anticipated between this proof of concept test and an in-situ field trial. A field-based demonstration style version of the Wicking Tank is planned for construction and testing in 2015.
\end{abstract}

Keywords: stormwater detention; stormwater re-use; urban trees; WSUD; drought; water security; hydraulic redistribution; wicking 


\section{Introduction}

Over the last twenty years, the Water Sensitive Urban Design (WSUD) has arisen in response to the need to address stormwater issues related to urban developments. WSUD is the integration of urban planning with the management, protection and conservation of the urban water cycle that ensures urban water management is sensitive to natural hydrological and ecological processes [1]. WSUD treatment devices are often used to aid the restoration of natural drainage catchment properties [2]. In vegetated WSUD devices, stormwater permeates through media where it is filtered through various layers and then either harvested for reuse through an underlying reservoir or released into the underlying soil or downstream stormwater drainage system [3].

WSUD systems are capable of mimicking natural hydrologic systems by water retention at source, maintenance of lag times for water transition through the catchment, and pollution control [1]. Vegetated WSUD systems can also make positive contributions to the broader restoration of natural ecosystem processes, by supporting trees and habitats in urban areas [4] and contributing to the remediation of streams draining urban land suffering from ecological degradation known as Urban Stream Syndrome [5].

Individual urban trees may offer the same or improved environmental benefits as vegetated WSUD systems, such as bio-retention systems and vegetated swales, and they may do so without taking up limited urban space, and due to their more extensive root systems, urban trees may also be more drought tolerant than other types of urban vegetation [6,7]. However, the maintenance of healthy urban trees does require the provision of the basic requirements of plant growth. Soil conditions are critical for tree growth, most particularly air, nutrient and water availability [7-9].

Impervious surfaces that dominate urban areas, such as pavements and roads, are known to modify both the moisture content, and the chemical properties of soil below, often resulting in drier soils mainly due to reduced infiltration [8,9]. By changing the natural properties of existing soils, limitations may be placed on the natural growth rates of adjacent trees. While it is known that urban trees will experience environmental stress during different periods of the year due to water, oxygen or nutrient availability, exactly how the trees cope with and respond to these stresses is less well understood [10-12].

In relation to water, the close relationship between the canopy of trees and their root systems is known to be complex, species-dependent, and particularly important during and after periods of environmental stress $[9,10,13]$. Daily water use by trees is a complex process that is influenced by soil type, soil water availability, diurnal period, season, species, tree age, tree size, canopy size, temperature, pollution levels and a number of other individual tree specific reasons including individual stomatal responses to water availability $[8,14,15]$.

One potential solution to resolving part of the conflict between the conditions essential for tree growth (air, water, and nutrient availability), and impervious surfaces is to modify pavement designs to provide improved environmental conditions for tree growth compared to conventional pavement treatments. Several studies have focused on the potential of a range of media and pavement designs to increase street tree health including both Porch [16] and Denman [6], while Morgenroth and Buchan [17], Mullaney et al. [11] and Mullaney et al. [12] examined using permeable concrete to improve street tree health through increased water and air supply. Research into structural soils has also been conducted over the last 20 years to determine its potential to provide adequate rooting volume for urban trees while providing a load bearing structure [18]. Few studies have focused on the long term survival of urban 
trees and their water requirements, particularly in the face of the predicted longer dryer spells likely to result from climate change [19,20] and reduced potential for irrigation into the future [21].

\subsection{Hydraulic Redistribution}

Water distribution by plants roots has been observed for almost a century. It was reported by Magistad and Breazeale [22] and Breazeale [23] while conducting experiments to test whether soil could be moistened by roots if part of the root system had access to free water or moist soil. Roots were identified as "equalisers" of soil moisture. Further studies demonstrated transfer of water from one plant roots to those of another $[24,25]$ when roots of both plants were located in a dry compartment whilst only one plant had roots access to water.

Hydraulic redistribution is the movement of water from plant roots into soil with a lower relative water potential (drier soil). During their Utah desert study, Richards and Caldwell [26] found plants could partially rehydrate upper soil levels during the night, resupplying water via plant roots to soil closer to the surface. This resulted in more water being accessible to plants for diurnal transpiration. They found that roots provided a pathway for the "equalisation" of soil-water potential across and between different soil layers. Through the night when plant transpiration was reduced, roots acted as wicks to transfer water from moister soil at depth and deliver it to dehydrated upper soil levels.

Hydraulic redistribution is generally known to be involved with the transfer of water from upper to lower soil layers in times of heavy rainfall. In addition to this, the movement of water has also been found to occur in all directions from moist soils to drier soils [27]. Hydraulic redistribution is the process by which water is transferred and stored for plant use in periods of drought [28,29]. Caldwell and Richards [30] found that water egress from roots was occurring overnight to be taken from the soil from the recipient plant roots directly.

The process of hydraulic redistribution has been recognised as important for ecological systems [31] and processes such as recruitment, nutrient cycling, and soil microbiology [32]. Although initially studied in deserts, hydraulic redistribution is not just restricted to arid or semi-arid environments and can reasonably be expected to occur in urban areas [33].

From the current understanding of the wicking capacity of trees and deeper rooted plants under natural conditions, without the soil-water equalisation process known as hydraulic redistribution, many soil profiles would be so desiccated from evaporation and transpiration by plants that many key ecological processes would be severely restricted [34]. Fundamental complex ecological processes of many plant genera have evolved to exploit the environmental niches created as a result of this water transfer processes [32,34].

Since the discovery of hydraulic distribution, many agriculturists have envisaged utilising this process in dryland cropping areas to improve crop yield. By using deep rooted nurse plants planted adjacent to crops, farmers hoped that the transfer of water from deeper soil would occur to support increased growth of profit yielding crops without additional irrigation. However despite the virtually unrestricted movement of water within, and throughout the soil profile, deep rooted plants have been found to be net users of water [34,35].

Lefroy and Hobbs [36] suggested that modified ecological systems, particularly agricultural, may be able to mimic the functional complexity of natural species assemblages to their advantage in resource 
limited environments. These concepts have been popular in relation to nutrient poor environments [37] where nutrient donor plants were planted and harvested alongside more valuable agricultural cropping plants. Water limited environments were examined by Sekiya et al. [38], who planted and harvested donor plants in order to re-supply adjacent crops with additional water drawn from beyond the reach of the crop plant roots. A study by Leffler et al. [39] showed that roots could continue to wick water up from depth after senescence, and suggested that even dead plant roots potentially play an important role in the survival of remaining plants during periods of drought.

Competition from shading and water use by nurse plants have been issues during these investigations as the prescribed symbiosis between donor nurse plant and crop were tested. Sekiya et al. [38] harvested the above ground biomass to reduce nurse plant water use and competitive shading during the cropping season with some success. Over the last three decades there has been a focus on investigating hydraulic redistribution due to the magnitude of the potential benefits of bio-irrigation for productive agricultural systems [33]. There have been few scientific studies applying this knowledge to urban environments in an attempt to resolve water security challenges faced by urban vegetation.

\subsection{Water Conservation by Plants}

Water conservation by plants has been studied in arid, and semi-arid environments because these ecosystems are characterised by periods of rainfall combined with periods of extended drought [40]. Many of these studies are relevant to the focus of this study because urban areas have modified environments that periodically resemble semi-arid environments. Short term plant responses to drought include plants that remain actively growing during periods of drought (drought tolerant rather than drought avoidant) and have well-developed active water conservation mechanisms [41]. These include stomatal control and leaf drop [30,42]. Once the plant senses water limitation, stomatal changes occur to reduce cavitation in the xylem vessels thereby limiting biological processes to physiologically manage the limited water supply.

Plants can also manage their water use over the longer term by modifying root:leaf ratios, reducing leaf size, producing less foliage, and constructing smaller xylem vessels to reduce the pace of water transport $[40,43]$.

Some tree species have been intimately linked with access to groundwater for survival [44]. When groundwater is depleted, riparian tree species have been shown to exhibit drought-stress responses including stomatal closure, reduced transpiration and photosynthesis, reduced predawn and midday water potentials, and xylem cavitation. Morphological responses including modified root growth, decreased shoot growth, and crown die-back can accompany these physiological responses. In some cases, tree death occurs [45].

\subsection{Convergence of Theory and Practice}

This research project builds on knowledge drawn from multiple disciplines including geology, soil science, engineering, WSUD, and plant biology. It represents an extension of the principles of engineered WSUD systems such as tree pits, and exploits the natural capacity of plants to respond to drought. It also incorporates the active facilitation of, and reliance on the natural processes known to 
occur in relation to water during hydraulic redistribution including capillarity, adhesion, cohesion and soil-water potential equalisation.

This paper reports on the development and testing of a newly developed WSUD device, the Wicking Tank (Figure 1). It is designed to supply sufficient volumes of water to urban trees via synthetic wicks from an underground storage tank to support adequate plant health during periods of drought. Stormwater is gravity fed to an underground water tank, and then through the natural capillarity, adhesion, and cohesion properties of water and the process of hydraulic redistribution, the water is transferred from the tank and into the rhizosphere of the tree (Figure 1). Water is only wicked up from the tank when local soil conditions in the tree rhizosphere dictate the need. Water demand is passively controlled by the water potential differential across the root zone. Although the rate of water transfer has yet to be field tested, theoretically the larger the water potential differential, the faster the water wicking rate from the tank.

The Wicking Tank translates the concept of natural donors (plants) supplying water and nutrients to recipient plants into an engineered solution, in an urban context. This involved the development, design and testing of a device inspired by, and based on the complex functioning and interactions of natural ecosystems. In particular, natural aquifers and hydraulic redistribution. Both natural systems and processes are known to make contributions to the survival of plant species through periods of drought through the processes of water collection, water storage and water delivery. The Wicking Tank replicates these functions.

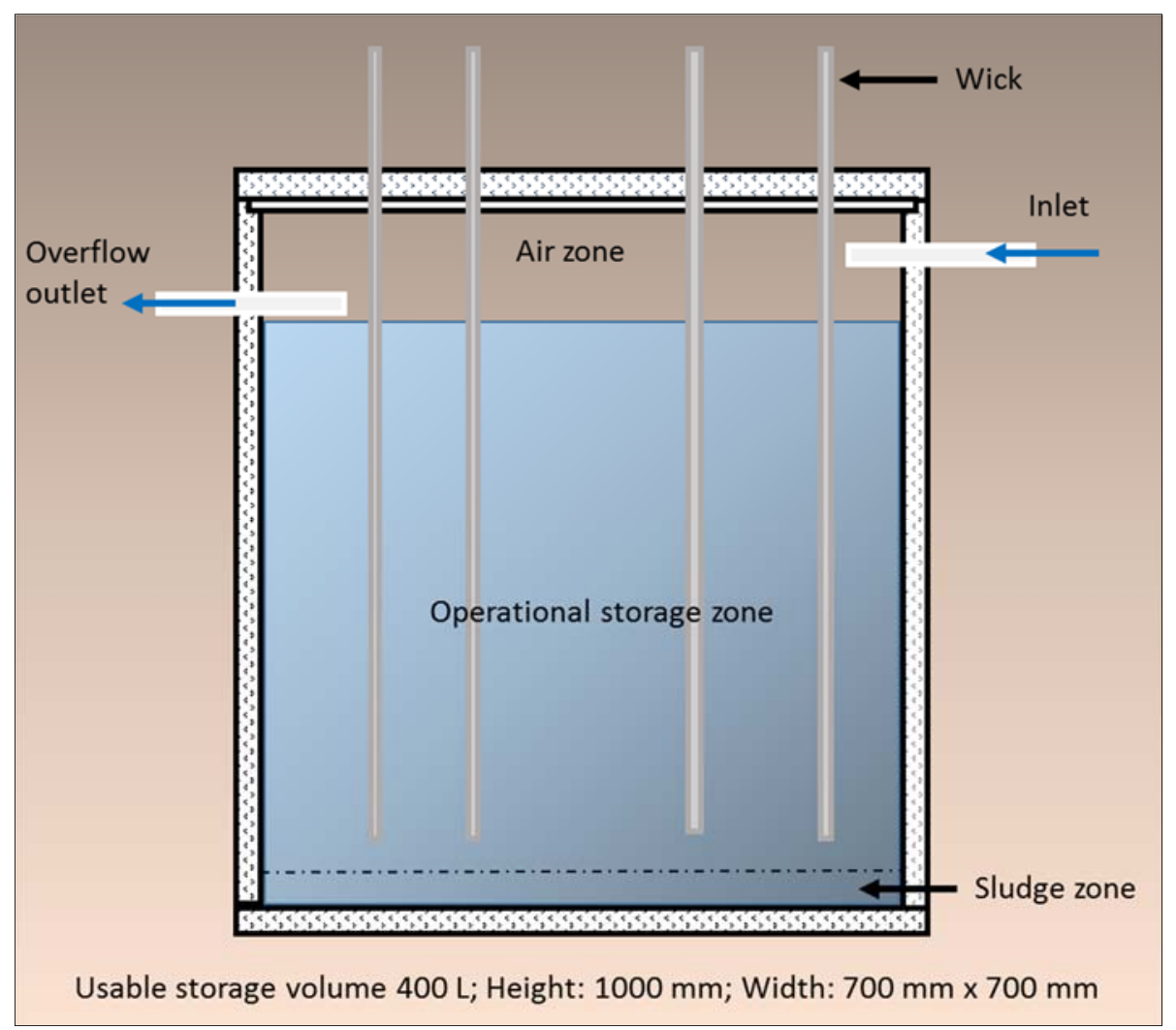

Figure 1. Schematic: Wicking Tank.

In order to investigate the viability of the idea, a proof of concept experiment of the Wicking Tank (Figure 1) was conducted at the University of Sunshine Coast Research Glasshouse during 2014. 


\section{Materials and Methods}

A series of pre-test trials were conducted on a range of wicking materials including cotton, geofabric, nylon, sand-filled pipe, thin plastic tube, and fibreglass to determine the best wicking material suitable for the intended purpose. Important elements considered during these trials included capacity and rate of water transfer (by wick diameter size) and minimisation of the potential for clogging by plant roots. These tests revealed the best performing wicks to be constructed of interwoven manufactured fibreglass. In addition, vacuum sealing the fibreglass wicks was found to increase wicking height and water volume transfer rates by $50 \%$.

The selected vacuum sealed fibreglass wicks (15 mm diameter) (Wickstore.com) were used to passively transfer water from a sealed chamber located vertically below to a potted plant above (Figure 2). Due to the range of possible hydraulic conductivity rates of different soil types, the experiment tested three different soils (clay loam, loam, clay sand). The maximum height of wicking was also investigated. Two wick heights, $0.70 \mathrm{~m}$, and $1.20 \mathrm{~m}$, were evaluated against controls. The glasshouse experiment excluded natural rainfall, and plants were not watered during the experiment. The only source of water available to the plants for the duration of the test was from the sealed water chamber, via the constructed wicks.

The experiment was conducted inside the University of Sunshine Coast Research Glasshouse to exclude natural rainfall. Tube-stock sized plants (Matt Rush, Lomandra longifolia) were grown in $300 \mathrm{~mm}$ diameter pots. This species was chosen as a proxy for a tree species due to its size, rapid growth rates, and hardiness. A sealed water chamber was constructed below the potted plants with a vacuum-sealed fibreglass wick running from the chamber to the inside of the pots (Figure 2). A replicated, orthogonal experimental design was developed to test for differences between treatments comprising five replicates, with one control per treatment.

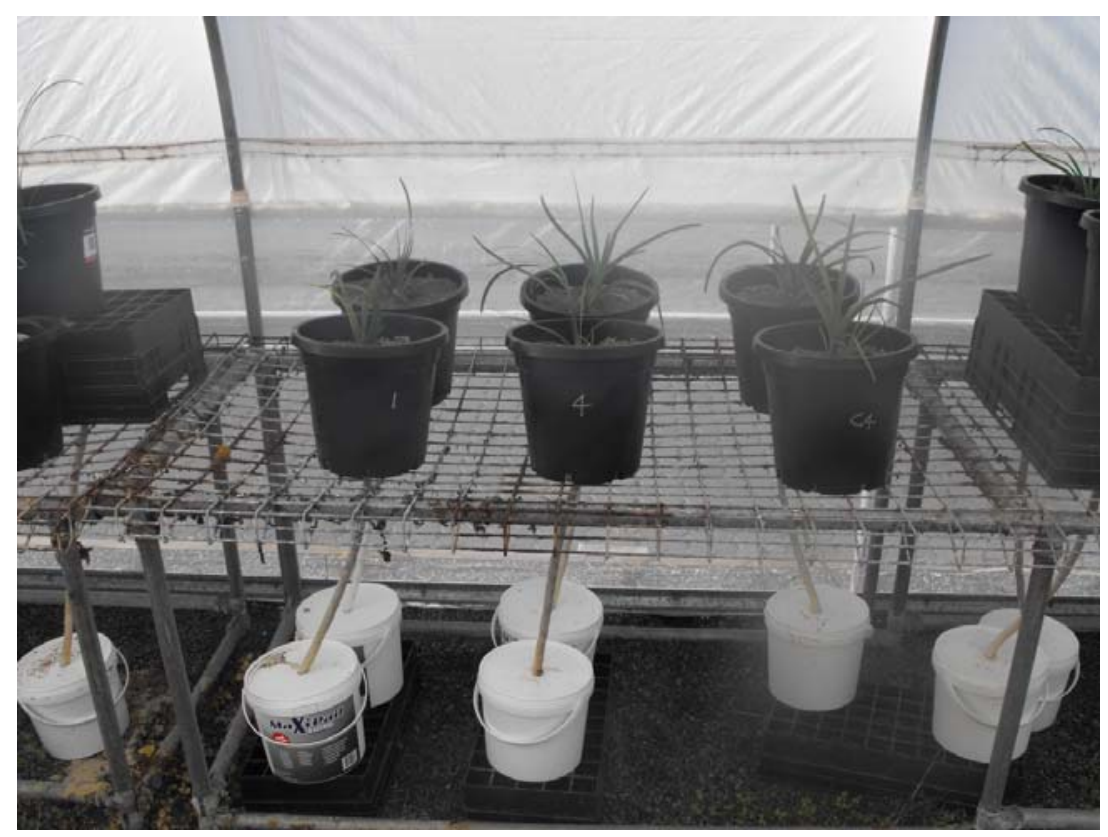

Figure 2. Wicking Tank pilot study experimental set-up. A sealed water chamber connected to the potted plant by a vacuum-sealed fibreglass wick to transfer water. The example shown here is the loam soil combined with short wick $(0.7 \mathrm{~m})$ treatment. 
Water use by plants was measured by weight (g) over a period of four months (August-December 2014). At the end of the study, plants were removed and oven dried. Roots and shoots of the plants were weighed after drying to compare plant performance subject to the different treatments. Higher root: shoot ratios are indicative of better plant health [46]. Root: shoot ratios were analysed and compared between treatments in order to determine which combination of wick length and soil type would be the most successful in terms of facilitating the movement of water from the sealed water chamber to the plant rhizosphere.

Daily volumes of water used via evapotranspiration by an individual tree has been estimated to vary between 0.2 L (1.5 m tall Eucalypt sapling) and 2000 L (mature aged, $100 \mathrm{~m}$ tall Dawn Redwood) [47]. By interpolation between those daily water use estimates, an average urban tree approximately $10 \mathrm{~m}$ tall with a canopy spread of $8 \mathrm{~m}$ may use between 30 and $150 \mathrm{~L}$ per day. This range is in line with other studies of water use by trees [48-50]. This gives an indication of total water use per day, per tree, displaying optimal growth. However, for the purposes of this pilot study, it is assumed that far less water is required for plant survival compared to optimal plant growth.

\section{Statistical Analysis}

To compare results between groups, arithmetic means and standard deviations of water use measurements were calculated for each of the treatments $(n=36)$. Using Plymouth Routines in Multivariate Ecological Research (PRIMER) [51], similarity matrices were calculated using the Bray-Curtis index from non-transformed plant dry weight measurements for all samples.

One-way ANOSIM analysis was used to explain the variation between treatments (soil type and wick length) using root and shoot dry weight measurements. No transformation and no standardisation of data was required. For interpretation, the Pairwise R values close to zero are indistinguishable, while values closer to 1 are separate (all similarities within groups are less than any similarities between groups). Two-way crossed ANOSIM analysis was used to determine whether other factors (water use) potentially affected dry weight measurement variations. Larger differences are revealed where Global R values are greater than 0.75 [51].

\section{Results and Discussion}

Total water use by plants over test period varied between $40 \mathrm{~g}$ and $190 \mathrm{~g}$ (Figure 3). Treatment results were highly variable between replicates. However there were also large differences between wick length, and between soil type treatments. Short wick lengths $(0.7 \mathrm{~m})$ consistently transferred a higher volume of water (up to $150 \%$ more) to plants over the duration of testing than long wicks (1.2 m in length). With a higher rate of hydraulic conductivity, the clay loam soil was observed to facilitate a higher volume of water transfer from the sealed chamber to the potted plant (230\% more than loam, $73 \%$ more than the clay sand). The wicking rate and height achieved during testing were possibly limited by a variety of factors including: the diameter of the wicks, and the natural adhesion, cohesion and capillarity properties of water. 


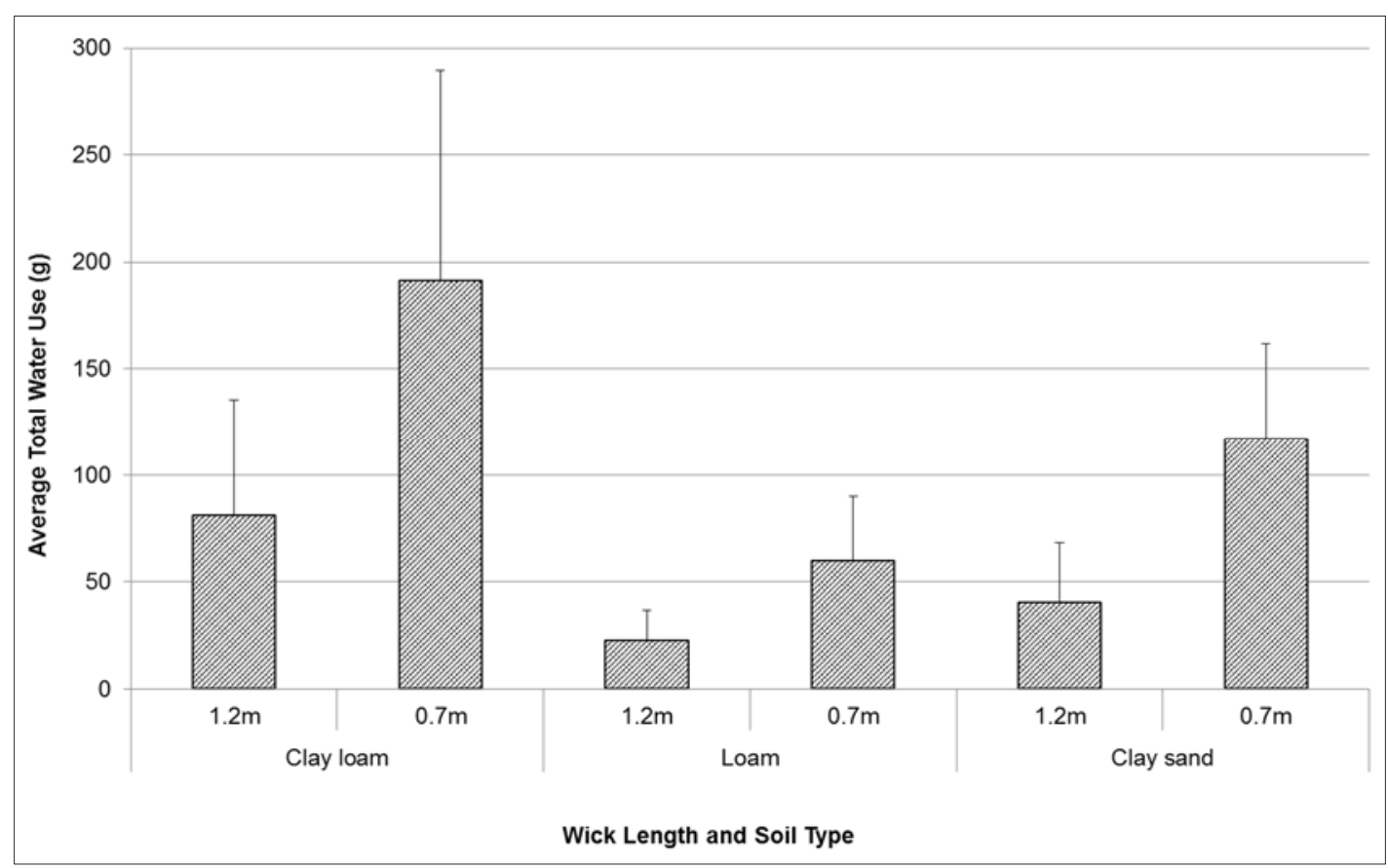

Figure 3. Comparison of mean (se) total water use (g) by Lomandra longifolia over 20 weeks (August-December 2014) using different wick lengths in three different soil media: clay loam, loam, and clay sand.

Plant performance during the experiment reflected the larger volumes of water being transferred to the potted plants via the wicks. Signifying better plant performance, the measured dry weight of roots and shoots were heavier in the clay loam soil combined with the short wick $(0.7 \mathrm{~m})$ treatment. There were no differences found between root and shoot dry weights between controls and any of the soil treatments combined with long wicks (Figure 4). Short wicks $(0.7 \mathrm{~m})$ were therefore more effective at transferring water to the potted plants to sustain plant life. Plant performance during testing was potentially affected by the species chosen for analysis. Although the influence of the plant roots on the water potential differential within the soil was not measured during testing, a plant more responsive to changes in water availability may have responded differently to the test conditions.

While analysis of root: shoot ratios showed variable results, the combination of treatments where the largest volume of water was transferred and the best plant performance (highest root: shoot ratio in this context) were observed was the clay loam soil combined with a short wick (Figure 5). A higher proportion of clay in the soil particle size distribution facilitated increased volumes of water transfer through the wick to soil. This result is consistent with the known the properties of water including adhesion, cohesion and capillarity. Any future installation of a wicking tank should be back-filled, and top dressed with a clay loam soil layer. 


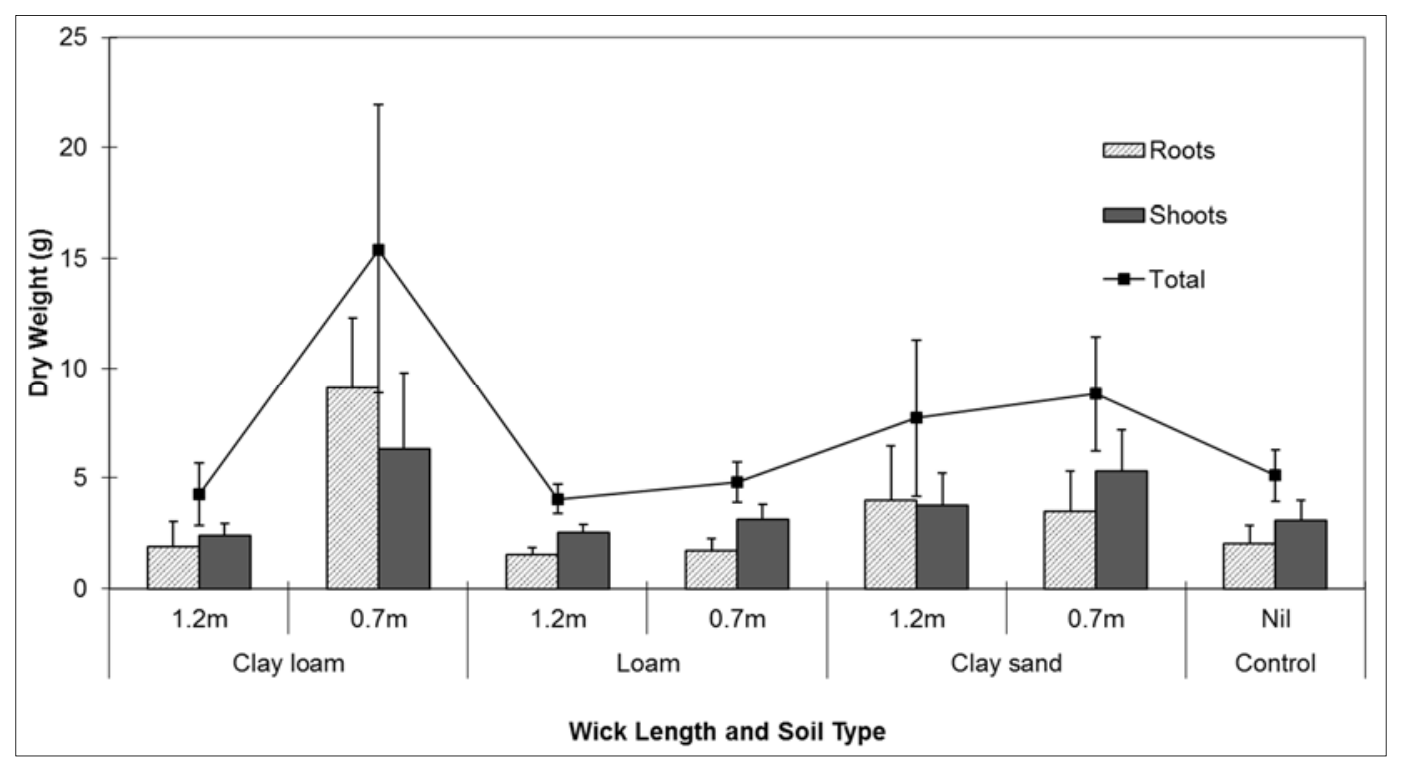

Figure 4. Comparison of mean (se) root and shoot dry weight (g) Lomandra longifolia using different wick lengths in three different soil media: clay loam, loam, and clay sand.

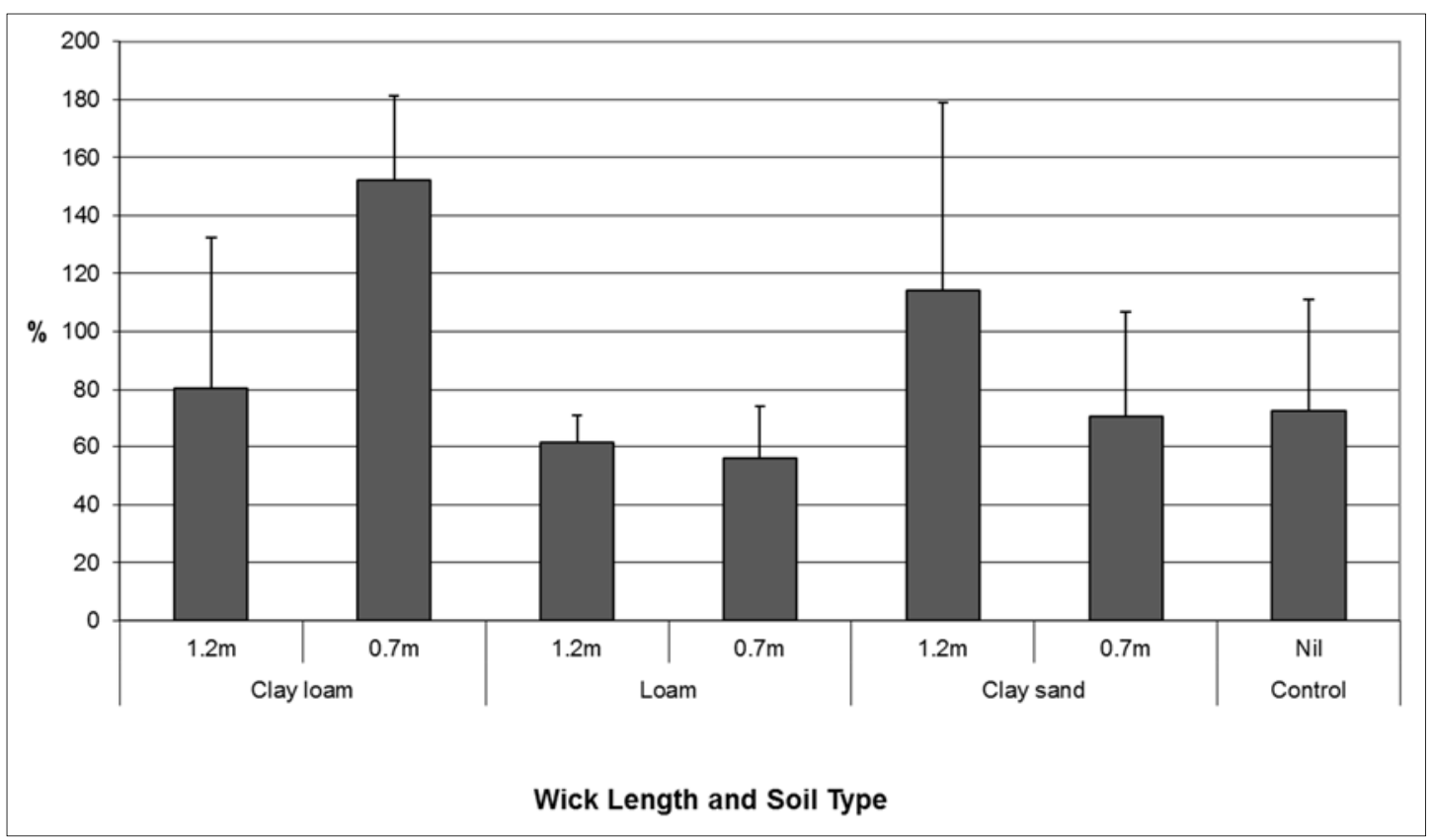

Figure 5. Comparison of mean (se) root: shoot ratio of Lomandra longifolia using different wick lengths in three different soil media: clay loam, loam, and clay sand.

Although ANOSIM revealed no significant differences between soil type treatments (Global $\mathrm{R}=0.16$, $p=3.6$ ), or between wick length treatments (Global $\mathrm{R}=0.044, p=1.2$ ), pairwise tests revealed large differences between long wick and short wick treatments, and short wick and no wick treatments (Table 1). There was no difference observed between long wick and no wick treatments (Table 2). Two-way crossed ANOSIM tests revealed no significant differences between wick length groups averaged across soil type groups (Global $\mathrm{R}=0.31, p=2.3$ ) (Table 1 ), nor between soil type groups averaged across wick length groups (Global $\mathrm{R}=0.348, p=1.5$ ) (Table 2). 
Table 1. Two-way Crossed ANOSIM tests between wick treatment groups.

\begin{tabular}{ccc}
\hline Groups & R Statistic & Significance Level \\
\hline Long wick/short wick & 0.351 & 0.7 \\
Long wick, No wick & 0.148 & 19.7 \\
Short wick, No wick & 0.37 & 2.9 \\
\hline
\end{tabular}

Table 2. Two-way Crossed ANOSIM tests between soil type treatment groups.

\begin{tabular}{ccc}
\hline Groups & R Statistic & Significance Level \\
\hline Clay loam, Loam & 0.375 & 1.48 \\
Clay loam, Clay sand & 0.231 & 2.48 \\
Loam, Clay sand & 0.463 & 0.248 \\
\hline
\end{tabular}

The capacity for wicking water from a sealed chamber to the rhizosphere of a plant is possible, however limited by several factors. There appears to be a maximum wicking height limitation of approximately $0.70 \mathrm{~m}$. Although untested, it may be possible for this height to be increased with further enhancements to the wicks, such as a wetting agent.

The soil type surrounding the wick (below the plant) also plays a pivotal role in aiding the mechanics of hydraulic redistribution and supporting water movement. A greater proportion of clay in the particle size distribution of the soil appears to support greater water volume movement up the wick, aiding the cohesion, adhesion and capillary movement of water.

The practical challenge of maintaining the wick free of roots which may clog the wick outflow area and decrease useful lifespan has also been under consideration. Potential solutions to prevent clogging are currently undergoing testing. These include charging the wick with plant growth hormones/retardants (synthetic cytokinins, Jasmonic acid, and Gibberellic acid- GA3) [52].

Proof of concept testing of a new WSUD device for drought-proofing urban trees has shown the device to successfully draw water to a height of $0.7 \mathrm{~m}$, and into soil to support the ongoing survival of a potted plant for over 20 weeks. Although further design and testing of the Wicking Tank is required to confirm performance in the field, the concept development phase of this study has found this stormwater capture and detention system designed to drought-proof urban trees may be a viable WSUD device. Further investigation regarding the volumes of water required to support optimum growth are required. The maintenance of adequate water quality during potentially lengthy storage periods also requires further investigation. Substantial differences are anticipated between this proof of concept test and an in-situ field trial. A field-based demonstration style version of the Wicking Tank is planned for construction and testing in 2015.

\section{Conclusions}

Proof of concept testing of a new WSUD device for drought-proofing urban trees has shown the device to successfully draw water from a sealed chamber to a height of $0.7 \mathrm{~m}$, and into soil to support the ongoing survival of a potted plant for over 20 weeks. 
The advantages of the Wicking Tank stormwater capture and detention system designed to drought proof urban trees includes:

- Efficient local level collection and use of stormwater;

- Aids in the restoration of urban stream syndrome;

- Capacity for manually refilling of water storage tank;

- Low-technology system with no moving parts; and

- Automatic low-technology, self-managed system.

The review of existing information available undertaken as a part of this study has highlighted the need for further research into the impact of developed urban areas on the natural water cycle and the potential consequences for urban vegetation.

\section{Acknowledgments}

The authors would like to thank University of the Sunshine Coast technical staff, including Bernhard Black, for their assistance in constructing the test equipment. We would also like to sincerely thank the Sunshine Coast Council for their assistance, and funding of this study. This research project is also supported by an Australian Research Council grant (No. LP120200678).

\section{Author Contributions}

Peter Nichols prepared the manuscript and assisted with data collection. Terry Lucke contributed to manuscript preparation and data collection and supervised the research. Both authors contributed equally to the manuscript.

\section{Conflicts of Interest}

The authors declare no conflict of interest.

\section{References}

1. Commonwealth Scientific and Industrial Research Organisation (CSIRO). Victorian Committee: Urban Stormwater: Best-Practice Environmental Management Guidelines; CSIRO Publishing: Clayton, Australia, 1999.

2. Fassman, E.; Blackbourn, S. Urban Runoff Mitigation by a Permeable Pavement System over Impermeable Soils. J. Hydrol. Eng. 2010, 15, 475-485.

3. Lucke, T.; Beecham, S. Field Investigation of Clogging in a Permeable Pavement System. J. Build. Res. Inf. 2011, 39, 603-615.

4. Argue, J.R. Going with the flow. In Proceedings of the 7th National Street Tree Symposium, TREENET, Adelaide, Australia, 7-8 September 2006.

5. Walsh, C.J.; Roy, A.H.; Feminella, J.W.; Cottingham, P.D.; Groffman, P.M.; Morgan, R.P. The Urban Stream Syndrome: Current Knowledge and the Search for a Cure. J. N. Am. Benthol. Soc. 2005, 24, 706-723. 
6. Denman, L. Are street trees and their soils an effective stormwater treatment measure? In Proceedings of the 7th National Street Tree Symposium, TREENET, Adelaide, Australia, 7-8 September 2006.

7. Mullaney, J.; Lucke, T. Practical Review of Pervious Pavement. Clean- Soil Air Water 2013, 41, $1-14$.

8. May, P. Soils, Water and Tree Establishment. In Proceedings of the 5th National Street Tree Symposium, TREENET, Adelaide, Australia, 2-3 September 2004.

9. Morgenroth, J.; Buchan, G.; Scharenbroch, B.C. Belowground effects of porous pavements-Soil moisture and chemical properties. Ecol. Eng. 2013, 51, 221-228.

10. Moore, G.M. Tree root networks: A vital ingredient of TREENET. In Proceedings of the 2nd National Street Tree Symposium, TREENET, Adelaide, Australia, 6-7 September 2001.

11. Mullaney, J.; Lucke, T.; Trueman, S.J. A review of benefits and challenges in growing street trees in paved urban environments. Landsc. Urban Plan. 2014, 134, 157-166.

12. Mullaney, J.; Lucke, T.; Trueman, S.J. The effect of permeable pavements with an underlying base layer on the growth and nutrient status of urban trees. Urban For. Urban Green. 2015, 14, 19-29.

13. Leers, M. Tree establishment in the urban environment. In Proceedings of the 14th National Street Tree Symposium 2013, TREENET, Adelaide, Australia, 5-6 September 2013.

14. Wang, H.; Ouyang, Z.; Chen, W.; Wang, X.; Zheng, H.; Ren, Y. Water, heat and airborne pollutants effects on transpiration of urban trees. Environ. Poll. 2011, 159, 2127-2137.

15. Eamus, D. Carbon and water fluxes of trees. In Proceedings of the 8th National Street Tree Symposium, TREENET, Adelaide, Australia, 6-7 September 2007.

16. Porch, S.; Zanker, J.; Pezzaniti, D. Stormwater harvesting trials for "irrigation" of street trees and water quality and quantity improvement. In Proceedings of the 4th National Street Tree Symposium, TREENET, Adelaide, Australia, 4-5 September 2003.

17. Morgenroth, J.; Buchan, G.D. Soil moisture and aeration beneath pervious and impervious pavements. Arboric. Urban For. 2009, 35, 135-141.

18. Smiley, E.T.; Calfee, L.; Fraedrcih, B R.; Smiley, E.J. Comparison of structural and noncompacted soils for trees surrounded by pavement. Arboric. Urban For. 2006, 32, 164-169.

19. Bureau of Meteorology; Commonwealth Scientific and Industrial Research Organisation. State of the Climate (No. 210252661); Commonwealth Scientific and Industrial Research Organisation, CSIRO Publishing: Clayton, Australia, 2014.

20. Moore, G. Tree management for carbon, energy and drought efficiency. In Proceedings of the 8th National Street Tree Symposium, TREENET, Adelaide, Australia, 6-7 September 2007.

21. Fam, D.; Mosley, E.; Lopes, A.; Mathieson, L.; Morison, J.; Connellan, G. Irrigation of Urban Green Spaces: A Review of the Environmental, Social and Economic Benefits; Cooperative Research Centre for Irrigation Futures: Brisbane, Australia, 2008.

22. Magistad, O.C.; Breazeale, J.F. Plant and Soil Relations at and below the Wilting Percentage; Technical Bulletin 25; University of Arizona, College of Agriculture, Agricultural Experimental Station: Tucson, AZ, USA, 1929.

23. Breazeale, J.F. Maintenance of Moisture-Equilibrium and Nutrition of Plants at and below the Wilting Percentage; Arizona Agriculture Experimental Station, Technical Bulletin: Tucson, AZ, USA, 1930; Volume 29, pp. 137-177. 
24. Hansen, E.A.; Dickson, R.E. Water and mineral nutrient transfer between root systems of juvenile. Popul. For. Sci. 1979, 25, 247-252.

25. Corak, S.J.; Blevins, D.G.; Pallardy, S.G. Water transfer in an alfalfa/maize association: Survival of maize during drought. Plant Physiol. 1987, 84, 582-586.

26. Richards, J.H.; Caldwell, M.M. Hydraulic lift: Substantial nocturnal water transport between soil layers by Artemisia tridentata roots. Oecologia 1987, 73, 486-489.

27. Burgess, S.S.O.; Bleby, T.M. Redistribution of soil water by lateral roots mediated by stem tissues. J. Exp. Bot. 2006, 57, 3283-3291.

28. Hultine, K.R.; Scott, R.L.; Cable, W.L.; Goodrich, D.C.; Williams, D.G. Hydraulic redistribution by a dominant, warm-desert phreatophyte: Seasonal patterns and response to precipitation pulses. Funct. Ecol. 2004, 18, 530-538.

29. Burgess, S.S.O.; Adams, M.A.; Turner, N.C.; Ong, C.K. The redistribution of soil water by tree root systems. Oecologia 1998, 115, 306-311.

30. Caldwell, M.M.; Richards, J.H. Hydraulic lift: Water efflux from upper roots improves effectiveness of water uptake by deep roots. Oecologia 1989, 79, 1-5.

31. Horton, J.L.; Hart, S. Hydraulic lift: A potentially important ecosystem process. Trends Ecol. Evol. 1988, 13, 232-235.

32. Burgess, S.S.O. Can hydraulic redistribution put bread on our table? Plant Soil 2011, 341, 25-29.

33. Caldwell, M.M.; Dawson, T.E.; Richards, J.H. Hydraulic lift: Consequences of water efflux from the roots of plants. Oecologia 1998, 113, 151-161.

34. Burgess, S.S.O. Facing the challenge of seasonally dry environments. Physiol. Plant. 2006, 127, 339-342.

35. Kulmatiski, A.; Beard, K.H.; Verweij, R.J.; February, E.C. A depth-controlled tracer technique measures vertical, horizontal and temporal patterns of water use by trees and grasses in a subtropical savanna. New Phytol. 2010, 188, 199-209.

36. Lefroy, E.; Hobbs, R. Agriculture as a Mimic of Natural Ecosystems. Workshop Report for the RIRDC/LWRRDC/FWPRDC Joint Venture Agroforestry Program Williams, Western Australia 2-9 September 1997; RIRDC: Barton, Australia, 1998.

37. Allen, A.S.; Schlesinger, W.S. Nutrient limitations to soil microbial biomass and activity in loblolly pine forests. Soil Biol. Biochem. 2004, 36, 581-589.

38. Sekiya, N.; Araki, H.; Yano, K. Applying hydraulic lift in an agroecosystem: Forage plants with shoots removed supply water to neighbouring vegetable crops. Plant Soil 2011, 341, 39-50.

39. Leffler, A.J.; Peek, M.S.; Ryel, R.J.; Ivans, C.Y.; Caldwell, M.M. Hydraulic redistribution through the root systems of senesced plants. Ecology 2005, 86, 633-642.

40. Smith, W.K.; Nobel, P.S. Influences of Seasonal Changes in Leaf Morphology on Water-Use Efficiency for Three Desert Broadleaf Shrubs. Ecology 1977, 58, 1033-1043.

41. Turner, N. Adaptation to Water Deficits: A Changing Perspective. Funct. Plant Biol. 1986, 13, 175-190.

42. Sperry, J.S.; Hacke, U.G.; Oren, R.; Comstock, J.P. Water deficits and hydraulic limits to leaf water supply. Plant Cell Environ. 2002, 25, 251-263.

43. Kolb, K.J.; Sperry, J.S. Differences in drought adaptation between subspecies of sagebrush (Artemisia tridentata). Ecology 1999, 80, 2373-2384. 
44. Webb, R.H.; Leake, S.A. Groundwater and surface water interactions and long-term change in riverine riparian vegetation in the southwestern United States. J. Hydrol. 2006, 320, 302-323.

45. Amlin, N.M.; Rood, S.B. Drought stress and recovery of riparian cottonwoods due to water table alteration along Willow Creek, Alberta. Trees 2003, 17, 351-358.

46. Davidson, R.L. Effects of soil nutrients and moisture on root/shoot ratios on Lolium perrene L. and Trifolium repens L. Ann. Bot. 1969, 33, 571-577.

47. Forster, M. University of Queensland, Brisbane, Australia. Daily tree water use estimates using sap flow meter technology. Personal communication, 24 September 2013.

48. Connellan, G. Water management strategies for urban trees in an uncertain environment. In Proceedings of the 9th National Street Tree Symposium, TREENET, Adelaide, Australia, 4-5 September 2008.

49. De Costa, W.A.J.M.; Amaratunga, K.S.P.; Udumullage, R.S. Transpiration Characteristics of Some Homegarden Tree Species in Central Sri Lanka; Springer: Houten, The Netherlands, 2006.

50. Wullschleger, D.S.; Meinzer, F.C.; Vertessy, R.A. A review of whole-plant water use studies in trees. Tree Physiol. 1998, 18, 499-512.

51. Clarke, K.R. Non-parametric multivariate analyses of changes in community structure. Aust. J. Ecol. 1993, 18, 117-143.

52. Li, G.; Zhu, C.; Gan, L.; Ng, D.; Xia, K. GA3 enhances root responsiveness to exogenous IAA by modulating auxin transport and signaling in Arabidopsis. Plant Cell Rep. 2015, 34, 483-494.

(C) 2015 by the authors; licensee MDPI, Basel, Switzerland. This article is an open access article distributed under the terms and conditions of the Creative Commons Attribution license (http://creativecommons.org/licenses/by/4.0/). 